\title{
Article \\ Street Verge in Transition: A Study of Community Drivers and Local Policy Setting for Urban Greening in Perth, Western Australia
}

\author{
Shania Hunt ${ }^{1}$, Jeremy Maher ${ }^{2}$, Mohammad Shahidul Hasan Swapan ${ }^{1}$ (D) and Atiq Zaman ${ }^{1, *(D)}$ \\ 1 School of Design and the Built Environment, Curtin University, Bentley, WA 6102, Australia; \\ shania.hunt@student.curtin.edu.au (S.H.); m.swapan@curtin.edu.au (M.S.H.S.) \\ 2 Water Corporation, Leederville, WA 6007, Australia; jeremy.maher@curtin.edu.au \\ * Correspondence: atiq.zaman@curtin.edu.au; Tel.: +61-8-9266-9018
}

check for

updates

Citation: Hunt, S.; Maher, J.; Swapan, M.S.H.; Zaman, A. Street Verge in Transition: A Study of Community Drivers and Local Policy Setting for Urban Greening in Perth, Western Australia. Urban Sci. 2022, 6, 15. https://doi.org/10.3390/ urbansci6010015

Academic Editor: Antonio Marco Pantaleo

Received: 1 December 2021 Accepted: 10 February 2022 Published: 25 February 2022

Publisher's Note: MDPI stays neutral with regard to jurisdictional claims in published maps and institutional affiliations.

Copyright: (C) 2022 by the authors. Licensee MDPI, Basel, Switzerland. This article is an open access article distributed under the terms and conditions of the Creative Commons Attribution (CC BY) license (https:// creativecommons.org/licenses/by/ $4.0 /)$.

\begin{abstract}
The United Nations' Sustainable Development Goals (SDGs) are regarded as the key policy agenda for national, regional, and local government to combat climate change impacts and promote sustainable development. For example, in Perth and Peel metropolitan area, the capital city of Western Australia, there has been a shift of policy setting from that of a sprawling city to a denser city, while maintaining and promoting its ecosystem services and achieving sustainable city goals. Residential verge gardens have been widely adopted in recent years by communities and local governments in the Perth metropolitan area. This study reviews the motivations and drivers for the uptake of verge gardens in metropolitan suburbs and identifies potential policy responses. The City of Bayswater local government area was surveyed for this research. The study considers a mixed-methods approach, including site auditing and a questionnaire survey for local residents who have transformed their verges. A total of 534 verge gardens were audited on residential lots, and 166 valid questionnaire responses were received from residents. The site-audit of the verge gardens in Bayswater found that native vegetation is the dominant verge garden of choice, followed by the ornamental garden, with food production (plants/vegetables) seeming to be the least popular option. Regarding the motivations and drivers, the study has found that social (e.g., aesthetics, flowers, social interactions, and social mimicry), environmental (e.g., attracting wildlife and birds and environmental practice waterwise garden), and personal (easy maintenance) drivers are the primary motivators for residents to adopt verge gardens. Whilst the on-ground surveys were prior to COVID-19, the article includes how this topic could relate to pandemic-resilient urban spaces. As local governments look towards supporting the sustainable outcome goals, the observations of this study will be helpful for developing local government policy and community programs in the promotion and uptake of verge gardens in Australian cities.
\end{abstract}

Keywords: verge gardening; urban greening; sustainable community; sustainable city; SDG 11

\section{Introduction}

The growing interest in sustainability and climate resilience has increased community demand for new and innovative green initiatives. The uptake of new green infrastructure and initiatives has the potential to meet several targets of the United Nations' Sustainable Development Goals, including sustainable cities and communities (SDG 11), climate action (SDG 13), and life on land (SDG 15). There is an increasing trend of urban greening amongst Australian cities through designated and formal parks, street trees, and retaining urban forests and bushlands. Individual interventions in local area greening on informal space (e.g., residential street verges and street medians) are gaining increased attention from policymakers and academics. It is contended that this underutilised space on residential lots could offer a range of ecosystem services if converted into a garden and equipped with water-sensitive features. Despite the potential environmental and social values of street 
verges, there is limited research which considers the factors and challenges affecting the uptake of this emerging green practice.

There is a growing popularity for verge gardening, which contributes to microecosystems in Australian suburbs. The verge is the area of land between the street edge and property boundary (Figure 1). This land is usually on public land and usually owned by the crown or council. Typically, this space is maintained by the adjacent property owner. Verges are generally overlooked in terms of maintenance and investment and are often overlooked as a public resource [1]. A verge is where further public value can be unlocked by increasing amenity, cooling our surroundings, or providing nature links with fauna-friendly vegetation [2]. All-important thinking towards 2031 and the climate change adaption or urban resilience are required in this climate emergency.
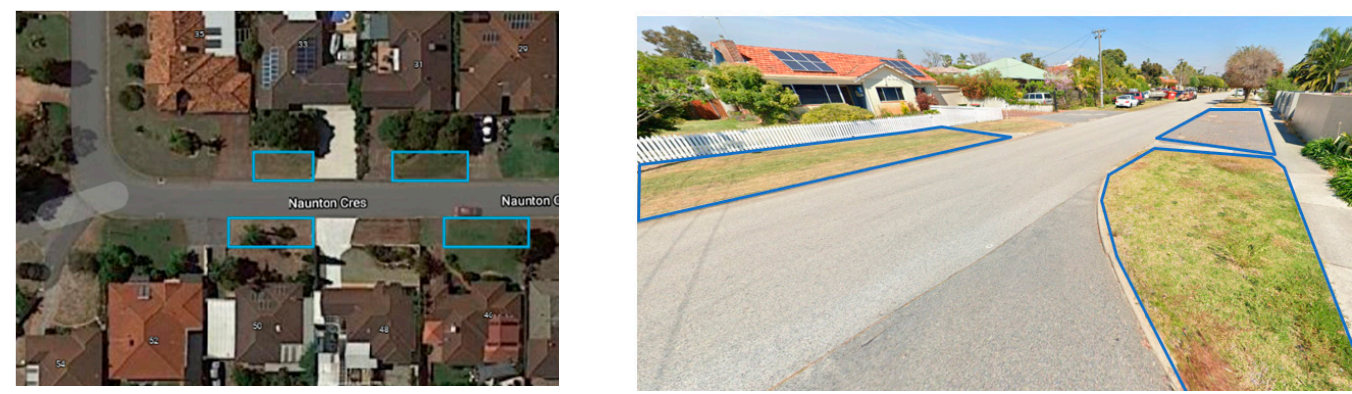

Figure 1. Aerial and horizontal views of residential street verges (collected from Google Maps).

Verge gardens may also be able to support an urban response to the current Anthropocene. Insects are the foundation of our ecosystems, and they provide vital functions, such as pollination, seed dispersion, population control, providing nutrients, and becoming a food source [3]. The current decline in insect population has been driven by habitat change and pollution. Globally, almost half of insect species are rapidly declining, and one third of all species are threatened by extinction [4]. In recent times, Western Australia's insect population was devastated by mega-fires, with roughly $100,000 \mathrm{~km}^{2}$ of native habitat lost in 2019-2020 [5]. The verge garden may be a natural link for native Australian insects and demonstrates how green spaces can have a much greater impact than anticipated.

While urban greening interventions tend to focus on formal public spaces (parks, bushland, and street trees), many researchers have turned their attention to the considerable potential of the residential landscape in regard to conservation management. Private gardens are a major asset to cities and can substantially impact urban biodiversity [6]. For example, the ReWild project in Perth (Western Australian capital city) aims to encourage the creation of native habitats in residential gardens in order to respond to the city's habitat fragmentation [7]. The growing pressure of limited space and environmental concerns sees the traditional turf suburban verge as a potentially lower value verge activity. Turf verges typically provide limited uses and require a large amount of water and fertiliser to keep alive due to Australia's climate [8]. In response, many local councils have transitioned to policies that support residents to better unlock this public, community, and resident value.

The planning strategy 'Perth and Peel at 3.5 million' sets the target to deliver 800,000 homes by 2050 through a mix of infill (47\% target) and greenfield (53\% target) [9]. A purposeful outcome of this policy is to provide stronger competition for land use in brown field suburbs. This has seen a refocusing by local governments and the community for how they can provide the triple bottom line outcome with proper planning. As property sizes reduce, urban planners look to where they can provide these traditional services, and also the emerging ecosystems. Historically, verge gardens were not encouraged, as the lower value of the verge land would result in business and psychological drivers that were not in their favour. Specifically, these needs were able to be accommodated in the larger backyards of that period and the perceived increased maintenance costs or root damage [10]. This change 
in competition for land has seen a rethinking of this value proposition by local governments and their communities, resulting in an increased local level appetite for re-greening verges.

In the last few years, a number of local councils in the Perth metropolitan area have created a verge garden-friendly policy [11], aiming to remove the constraints that prohibited a resident from creating a verge garden. However, there is limited academic knowledge on the complex environmental and social dynamics attached to the formation of appropriate policy instruments related to verge gardening. Two key research questions considered in this report are: 'what are the motivations and drivers of residences with verge gardens?' and 'how can local councils use this information to increase uptake of verge gardens?' To address these research questions, this paper focuses on the City of Bayswater geographic area (i) to explore the patterns of adoption (including the spatial distribution) and characteristics of verge gardening across the council and (ii) to understand community drivers (benefits, motives, and perceptions) and consideration of the policy setting to promote verge gardens. The study will help to identify a knowledge gap and will allow policymakers to better understand the trade-offs, benefits, and acceptance of green infrastructure.

\section{Study Context}

Over half the world's population (55\%) live in urban areas, and that is expected to rise to $68 \%$ by 2050 [12]. Australia is one of the most urbanised countries, with over $70 \%$ of residents living within capital cities [13]. Perth, has experienced some of the highest growth rates in Australia, with an annual increase of $1.8 \%$ [14]. In a local context, the recent strategic metropolitan plans (Directions 2031 and Perth and Peel at 3.5 million) set a strategic planning framework for Perth's anticipated growth of 35-40\%. The strategic plans suggest a more consolidated urban form to transform from the traditional low-density suburban development. One of the major targets is to increase the current residential density by $50 \%$, particularly in inner suburban areas [9]. This increased density is consistent with better planning outcomes; however, it is changing the Perth suburban landscape, resulting in the loss of the infamous 'Australian backyard', as well as trees and private green space in the dominant urban form. The pressures of population growth have put increasingly more stress on our local greenspaces and are beginning to be replaced with housing and commercial developments [15]. This form of urban density is also demonstrated to have an effect on already fragile ecosystem services [16]. The denser form without better planned quality green spaces, either private or public, could have negative impacts on community wellbeing [17]. There is also a significant urgency to consider the threat to cities from climate change and the need for more investigation on how nature-based solutions can provide some form of resilience to our cities.

Australia is one of the driest continents in the world, and our harsh climate makes the effects of climate change increasingly evident [18]. In Perth, there has been a 20\% decrease in rainfall and an increase in the intensity and frequencies of hot spells [1]. The effects of climate change will hurt not only the local environment but also human health. Extreme heat leads to an increased number of natural disasters that also affects local food supplies [19]. Urban greening is a popular strategy in reducing urban heat island effects and preparing cities to combat the impacts of climate change. While there is an increasing uptake of greening initiatives by the state, well-managed informal green space is becoming a popular practice at the household level for achieving environmental benefits and adapting to climate change. Looking to underutilised land in cities to provide better public value and ecosystem outcomes is critical in the public policy response.

\section{Literature Review}

\subsection{Benefits of Verge Gardens}

The increase of Perth's residential densities is resulting in greater land competition and consideration needs to be made for how cities can provide adequate green space. As part of the answer to this question, the authors highlight the opportunity to provide greens spaces in more informal places. A recent study was conducted in Perth around 
how stakeholders value verge gardens within an ecosystem context. These stakeholders include local governments, developers, community groups, and large corporations across Perth. There was an importance demonstrated by the different stakeholder groups and for different benefits [20].

There are a number of studies identifying the benefits of forests, public parks, and gardens, but there is less literature on informal spaces, including verge gardens [21]. The cumulative action of gardening practices, such as verge gardens, can greatly benefit our environment and human health [10]. The practice of gardening performs a vital function of city living enrichment and recovering of the natural environment [15]. Residential gardens form a significant portion of urban greenspace and are imperative for conservation and healthy ecosystem functionality [22]. The introduction of various species that are not typically found in native spaces can provide habitat and biodiversity and encourage pollinating insects [6]. An Australian study analysed the role of roadside vegetation in relation to native insects. Many factors affected the presence of insects, including landscape features, larvae habitat, nectar supply, herbicide use, and mowing [23]. This demonstrated that gardening practices could affect local wildlife and biodiversity, while bringing better habitats.

Vegetation in a densely populated area can provide many 'free' ecosystem services or benefits, such as the relief of the urban heat island effect. Urban greenspace provides the most natural and effective cooling benefits, with microclimate improvements by increasing shade and evapotranspiration [24]. Residential gardens with the correct planting layout have the ability to reduce the energy consumption of residential buildings by $20-40 \%$ by the cooling effects [25]. The cooling effects of gardens are becoming an increasingly important component for the benefit of humans and the environment; additionally, there is further research required to understand what air quality improvements may be possible at the street level.

Streetscapes play an important role in suburbs; they provide a space for social interactions and active and passive recreation, which can boost people's physical and psychological health. The presence alone of these gardens supports human wellbeing and health, community pride, and neighbourhood identity [22]. These gardens have been found to be an important place for interacting with nature, with the increase of urbanisation and decline of biodiversity.

Greenspace and its benefits are commonly discussed in non-economic values; however, it can also be assessed through monetary evaluations. A study in Shanghai (China) found that private greenspace increased housing prices by $8.7 \%$ [26], while an Australian study found that well-maintained landscaping can boost housing prices by up to 15\% [8]. Moreover, a recent project on urban stream rehabilitation in Perth put an economic value on the amenity provided by this greenspace. It was estimated that surrounding house prices increased up to $6 \%$ after 5 years of the project's completion [27]. Although these studies show obvious perceived benefits, these evaluations do not incorporate the complexity of greenspace. A non-monetary valuation of these benefits needs to be explored as capturing the benefit and value of ecosystem services in monetary terms does not fully reflect the character and perceived aspects of greenspace [27].

With the advent of the global pandemic of COVID-19, we are beginning to see in the literature the term 'pandemic resilient planning'. One particular paper references the idea of social distancing pods where streets and parks are designed to support social distancing in the public space. In particular, they discuss the role parklets may play in providing this urban form outcome [28]. Verge gardens are a social distancing pod opportunity at the suburban level, where they can provide increased 'socially distanced green spaces' as well as support existing footpaths and roads to be used for this purpose, with the green benefits of the verge garden. 


\subsection{Motives and Perceptions}

A study into prioritising the research on green infrastructure found that the forefront of green infrastructure design should reflect the needs and desires of the community [10]. A community-driven design outcome is critical for the long-term sustainability of the localised practice. Studies into greenspace typically find that cultural factors are a key component when the community is asked to value greenspaces [27]. Goddard and Dougill [6] found that the most valued aspect of wildlife-friendly gardens was their aesthetic appearance and flowers rated highly in importance. To correlate with this, a study into urban 'wastelands' found that a positive valuation was given if there was a higher presence of colorful flowers [20]. In our study, we found that aesthetics was a major driver of the uptake of verge gardens and shows the importance to local residences.

The role of social norms and peer pressure is noted in relation to verge gardens. The front gardens are often seen as a public display [6], while the backyard is a place for oneself to relax and express themselves [8]. Interestingly, a Melbourne (Australia) study found that people were hesitant to create verge gardens in fear of disapproval of neighbours [28]. These ideas demonstrate the impact of social norms on the uptake, maintenance, and even change the look of a verge garden. An important aspect of social norms is also the negative perceptions that can be linked with residential greenspace. Within the study of 'wastelands', there was a strong correlation between areas with low maintenance and no sightlines, which gave a negative perception [20]. This is consistent with crime prevention through environmental design (CEPTED) principles [29]. This gives us the understanding that unmaintained spaces can have both a negative community perception and CEPTED outcome, which can lead to issues of community safety if not managed.

\subsection{Policy Framework}

For the development of verge gardens, local governments in Western Australia are the best positioned to provide the appropriate policy setting and incentives for verge garden renewal. Over recent years, several Perth councils have demonstrated different approaches to how this can be provided. Many local governments have introduced extensive verge garden programs, that offer a variety of incentives to residents. For example, the City of Vincent offers to perform earthworks and the supply and installation of mulch, free of charge to the residents [30]. The City of Cockburn offers an AUD 250-500 rebate towards planting a waterwise verge garden [31]. These rebates are popular due to funding agreements with the Water Corporation (primary supplier of water, wastewater, and drainage services across the state of Western Australia) to contribute dollar-for-dollar (up to AUD 10,000 per local government) to these waterwise verge gardens [32].

A reoccurring theme within literature is the lack of knowledge around the benefits of verge gardens or, more broadly, green infrastructure $[6,20]$. This is increasingly becoming an area of academic research and a concern for planning practitioners. Educational instruments and information sharing have proven to be effective in providing residents with knowledge and understanding of what can be achieved within a verge to provide the most benefit [29].

A new way of thinking has been witnessed in the UK, with policymakers harnessing the idea of 'catalyst behaviours', which can provide positive follow-on effects and change wider behaviours [6]. In our study, we explored this idea by mapping the 'clustering' of verge gardens and their impact on neighbouring households. This idea presents the potential for using catalyst behaviours in the uptake of verge gardens through social mimicry. This could be achieved in a variety of ways and with minimal intervention from government authorities. One example could be creating a garden model to demonstrate the potential for gardens that are adapted to the local climate [21]. This would be carried out in hopes of a neighbourhood widespread of habitat linkage that is fully privately maintained. 


\section{Materials and Methods}

\subsection{Study Area}

The study was developed and conducted using a mixed-methods approach involving site-audit, observation, and a household questionnaire survey of the verge garden adopters. The Curtin Human Research Ethics Committee approved the research (approval no. HRE2019-0457). The study area is an urban local government located within the metropolitan area of Perth, Western Australia. The City of Bayswater has an area of $35 \mathrm{~km}^{2}$ as shown in Figure 2, with a population of 65,050 [33].

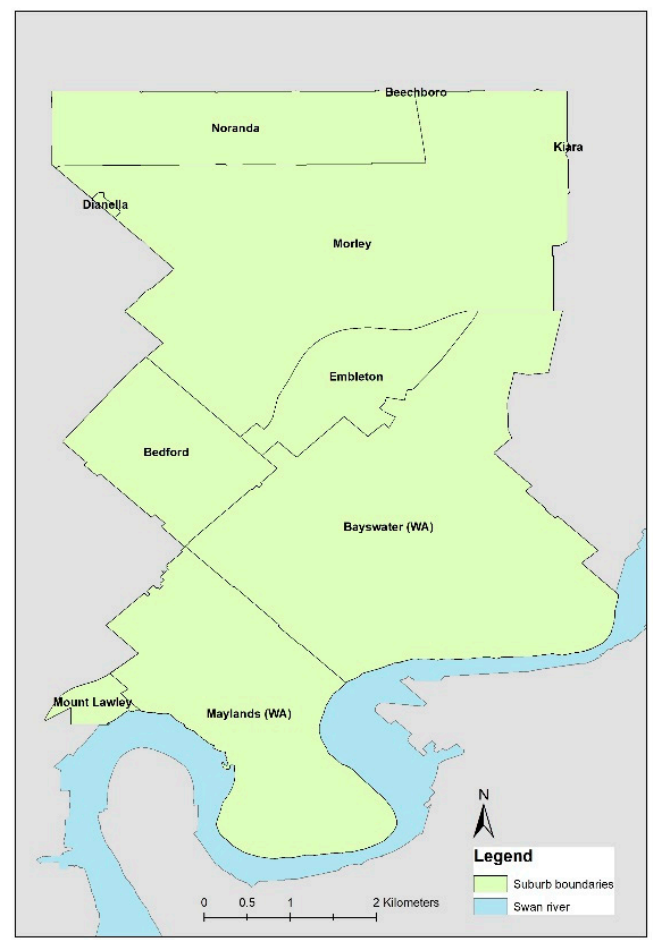

Figure 2. Location and administrative boundary of City of Bayswater [34]. Map is prepared from open-source data (Acknowledgement: Australian Bureau of Statistics and Department of Biodiversity, Conservation and Attractions).

The City of Bayswater local government area has a rich history, with the importance of the Swan River for the Indigenous Noongar people and western culture dating back to the 1800s. The southern portion of the area (Bayswater and Maylands) had Perth's key historical railway passing through, leaving historical housing behind [35]. The southern border of the council is the Swan River, and the northern border is a major highway. The northern portion of this council (Noranda and Morley) was developed during post-WWII with traditional low-density Australian suburban housing [35].

These two areas have different styles of housing and development. Figure 3 demonstrates the difference in housing patterns between the different suburbs. Older couples typically inhabit the northern suburbs, and the housing reflects the typical suburban Australian home, with single, separated dwellings and manicured lawns (a). Maylands is the densest suburb with many 3-4 story apartment blocks and unit subdivisions (b). Bayswater has older style housing with traditionally large blocks and smaller homes (c).

The socio-demographic factors between these two sections are quite different. The northern area has a lower median income of AUD 115 less per week [36]. The southern area has a younger median age, by 5 years $[33,37]$. The northern area has a higher proportion of older couples without children [34], while the southern area is younger couples with children $[33,37]$. Table 1 shows the differences between the two areas in terms of demographic characteristics, using Australian Census data. 
All 6531 residential lots were surveyed within the boundary of the City of Bayswater for the presence and characteristics of verge gardens (534) with a frequency of $8 \%$, shown in Figure 4.

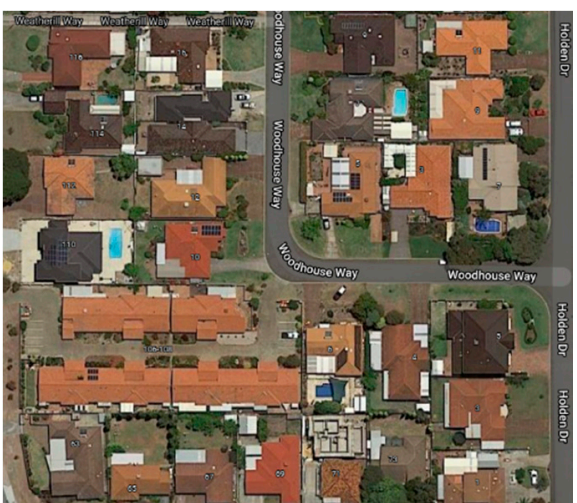

(a)

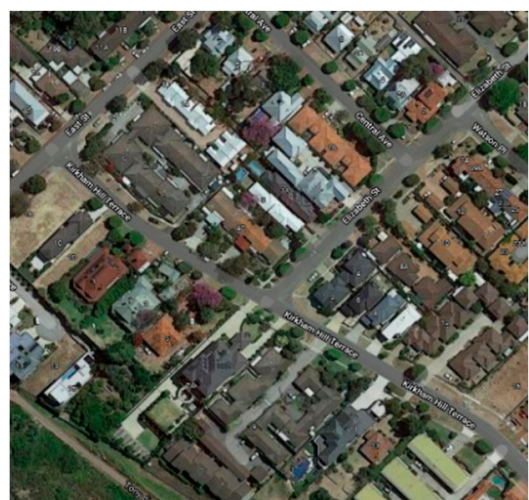

(b)

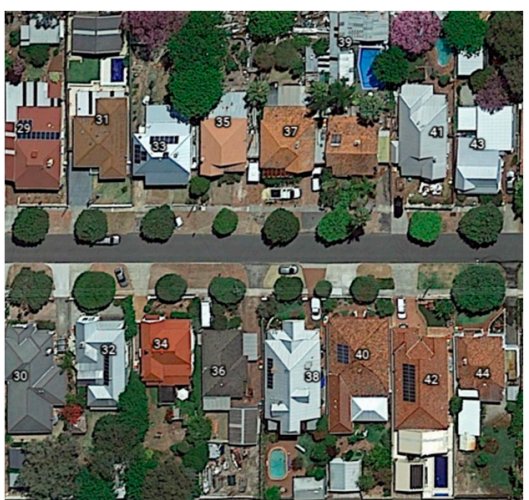

(c)

Figure 3. (a) Example of housing in Noranda (northern section); (b) example of housing within Maylands (southern section); (c) example of housing in Bayswater (southern section) (collected from Google Maps).

Table 1. Demographic information of areas within the City of Bayswater [35-37].

\begin{tabular}{ccccccc}
\hline Region & Population & Dwellings & $\begin{array}{c}\text { Median } \\
\text { Weekly Income }\end{array}$ & $\begin{array}{c}\text { Median } \\
\text { Age }\end{array}$ & $\begin{array}{c}\text { Average } \\
\text { Household Size }\end{array}$ & $\begin{array}{c}\text { Primary Housing } \\
\text { Density }\end{array}$ \\
\hline Northern Portion & 29,509 & 12,382 & AUD 1462 & 41 & 2.6 & Low \\
Southern Portion & 27,009 & 13,901 & AUD 1577 & 36 & 2.2 & Medium \\
\hline
\end{tabular}

\subsection{Auditing and Observational Survey}

An audit of all verge gardens within the City of Bayswater was conducted from November 2018 to February 2019. The first stage of this audit was a desktop study, using satellite imagery to identify potential verge gardens. Once these locations were found, a site survey was conducted.

A rapid verge garden assessment (RVGA) was developed and used for these saddle surveys (on bike and foot) recorded along with street address, photographs, and by noting the characteristics of the garden. The audit data was further added to a spatial database on ArcGIS platform showing the location of the verge garden and its attributes derived from the survey. The criteria of attributes that were recorded for the verge garden can be found in Table 2.

Table 2. Unit of measurement for the rapid verge garden assessment.

\begin{tabular}{ccc}
\hline Attributes & Measuring Unit/Features & Measure \\
\hline Garden size & Sq.m. $\left(\mathrm{m}^{2}\right)$ & Numeric Input \\
Vegetation type & Native, ornamental, waterwise, and food & Multiple Choice \\
Soil condition & Cultured, non-cultured, and mulch & Single Choice \\
Vegetation health & Healthy, fair, and unhealthy & Single Choice \\
\hline
\end{tabular}




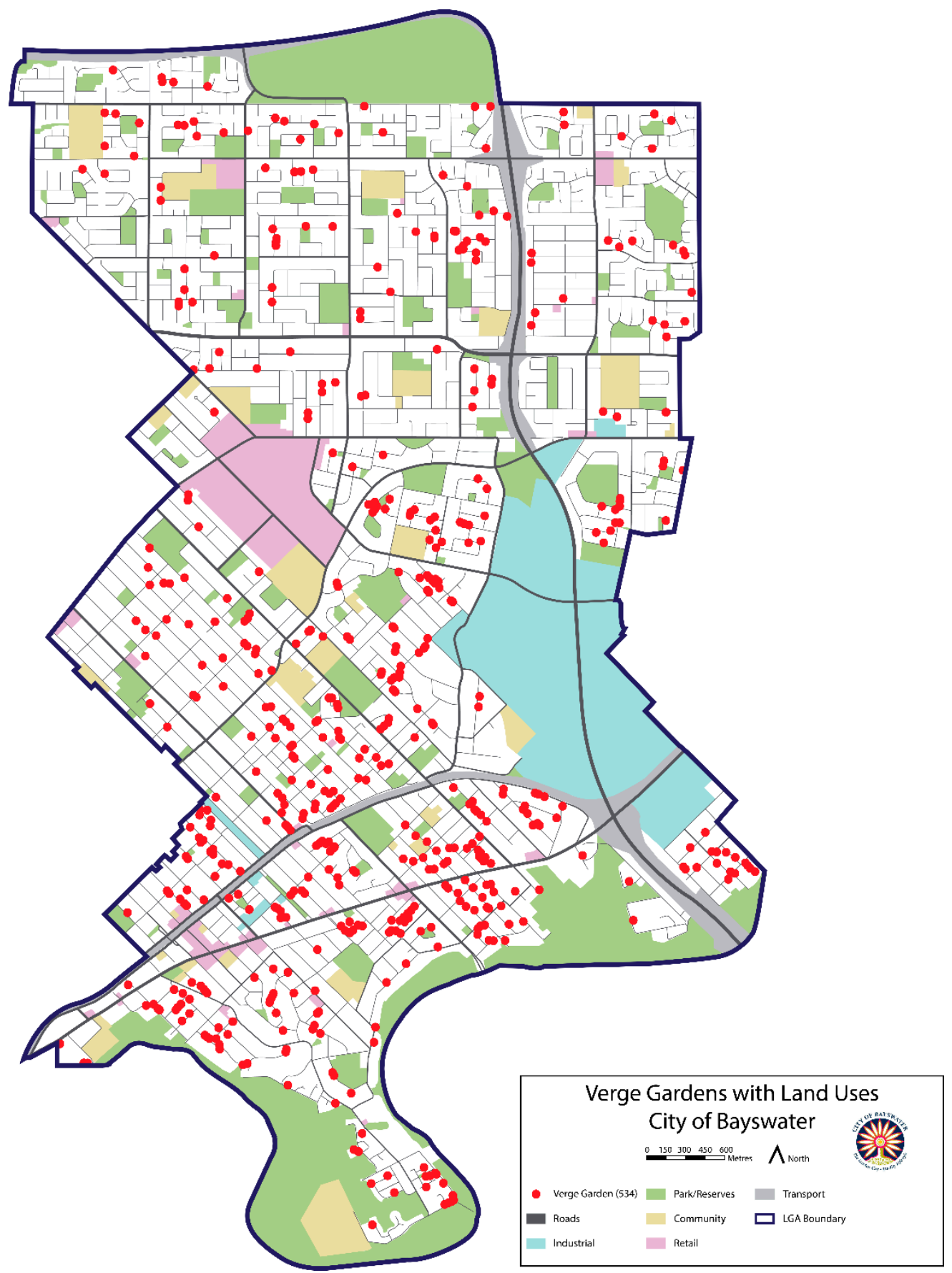

Figure 4. Location of verge gardens in the City of Bayswater.

In the RVGA, the verge was typically visually identified by the household's letterbox and other property line markers. A verge garden was identified if the majority of the verge was planted with non-turf vegetation. Many single-row plantings on the property line were not included. A limitation that presented itself was the presence of footpaths; if only a small portion of the verge was garden and the majority was footpath, these were not counted. The actual measurements of gardens were obtained on Google Earth from aerial photos and measurement tools.

The audit collected the type and health of vegetation within the verge gardens. Each garden could have up to three types of vegetation, including native, ornamental, waterwise, and food. These vegetation types were classified by the species present within the garden. 
Examples of these vegetation types can be seen in Figure 5. Each vegetation type can be classified with the breakdown below:

- Native vegetation contained plants, which were generally from the southwest of Australia (Figure 5a).

- Ornamental vegetation contained exotic plants, which generally did not originate in Australia and have a more 'traditional' style (cottage garden) (Figure 5b).

- Waterwise vegetation could contain any plant species deemed waterwise and this included plants from broader Australia or various cultivars and exotic plants, such as succulents (Figure $5 c$ ). Food vegetation is classified as gardens that were generally intended to be edible and for the purpose of food (Figure 5d).

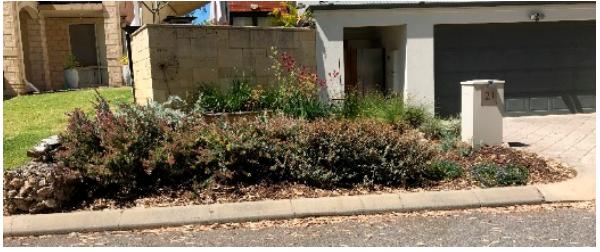

(a)

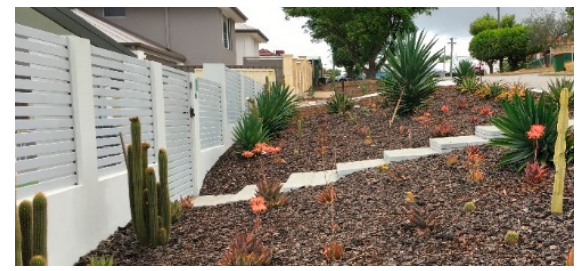

(c)

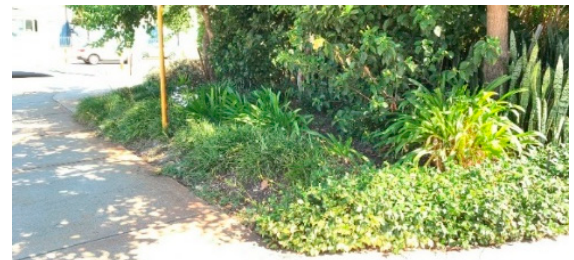

(b)

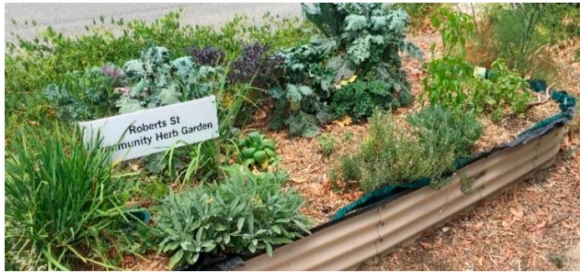

(d)

Figure 5. (a) Example of a native verge garden; (b) example of an ornamental garden with exotic species; (c) example of waterwise verge garden with mulch; (d) example of the food garden.

In developing the RVGA, it was noted that a complete botanical survey of each garden would be considered excessive or excess information for the purposes of this assessment. Additionally, it is commonplace for gardeners to use propagated varieties that are difficult to rapidly assess. As such, the broad categories were developed as intent of the garden as a whole; however, it is likely that a small range of species may have appeared at the individual site level.

The health of vegetation was carried out with a visual inspection. Healthy was classified with no dead plants and no/minimal weeds. A fair garden was classified as having a few dead plants and/or slightly unkempt. An unhealthy garden had the majority of plants as dead and/or severely unkempt.

\subsection{Questionnaire Survey on Verge Garden Adopters}

A questionnaire was hand-delivered to letterboxes with a paid return envelope to all verge garden adopters within the City of Bayswater. The questionnaire aimed to find details and perceptions of the residents who constructed verge gardens within the city. Due to time limitations of this study, non-adopters were not given a questionnaire. A non-adopter's questionnaire was planned for future research.

A total of 534 questionnaires were delivered, and 166 valid responses were returned. The questionnaire contained seven questions. The survey considered (i) motivators and drivers, and perceptions of verge gardens; (ii) associated time and costs to construct; and (iii) knowledge on current policy settings. The use of qualitative responses allowed for natural response [29], with further refinement to find the key information. The questionnaire was anonymous and did not ask for the respondent's name or house number. Respondents 
were also asked socio-demographic questions regarding suburb, age, occupation, house tenure, length of residency, and household size.

\section{Results}

\subsection{Verge Garden Characteristics}

The average size of a verge garden in the study area was $48 \mathrm{~m}^{2}$, ranging from $5 \mathrm{~m}^{2}$ to $310 \mathrm{~m}^{2}$. The dominant vegetation type noted was native $(63 \%, n=336)$. Ornamental vegetation was found in 51\% (275) of all gardens. Food production plants were the least popular vegetation type with $10 \%$ (51) of gardens. Around $62 \%$ of all verge gardens $(n=330)$ had a groundcover of predominantly mulch. A common occurrence was the use of mulch in native and/or waterwise gardens. Fertilisers and cultivated soils (12\%, $n=66$ ) were used in food and/or ornamental gardens. The remaining $25 \%$ (136) was noncultivated or natural soils. The vast majority of the plants in the gardens were considered healthy $(75 \%, n=403)$ with no dead plants or unkempt weeds. Of the gardens considered fair $(22 \%, n=118)$, a larger proportion $(38 \%, n=45)$ had non-cultured soil. Some variations were observed depending on the locality of the gardens. There was a higher concentration of gardens in the southern portion of the study area, while those were generally also larger than average. The northern portion was primarily ornamental gardens and had a higher proportion of healthier gardens.

\subsection{Spatial Distribution of Verge Gardens}

Social behaviours had an impact on the likelihood of a resident growing a verge garden. The authors looked for evidence of clustering or grouping of verge gardens within a walkable catchment. In the planning profession, a walkable catchment is a theoretical planning tool, which is a $400 \mathrm{~m}$ radius from the home or considered location. In general terms, a person can walk this distance within 5 min of their homes [38].

When measuring the density of verge gardens in a walkable catchment, it was found that there were an average of 13 gardens per $400 \mathrm{~m}$, ranging from 1 per $400 \mathrm{~m}$ to 37 per $400 \mathrm{~m}$. Figure 6 shows the densities of verge gardens, red being the highest density and blue being the lowest density.

Half of all verge gardens $(51 \%, n=270)$ had at least one other verge garden within a visual distance. This could include neighbouring properties on the same and opposite side of the road. Of those 270 verge gardens, 150 (56\%) of those were in a cluster of two, $72(27 \%)$ were in a cluster of three, and $48(16 \%)$ were in a cluster of four or more. The study revealed 14 visually apparent street clusters; although not all within visual distance, but there is an obvious street linkage (Figure 5). A common reason for such clustering was the installation of footpaths and planting after construction and the presence of an initial residents' garden.

There is an obvious apparent density difference between the southern and northern regions. Only one cluster is present within the northern area, with an average density of five verge gardens within $400 \mathrm{~m}$ of each other. The southern area is drastically different with 10 clusters and an average density of 17 per $400 \mathrm{~m}$. This is a proportional increase of $240 \%$ from the available data. Figure 7 shows the weekly income of households within the City of Bayswater and demonstrates that the clustering may be due to the higher income, density of homes, and increased land value of the southern area. 


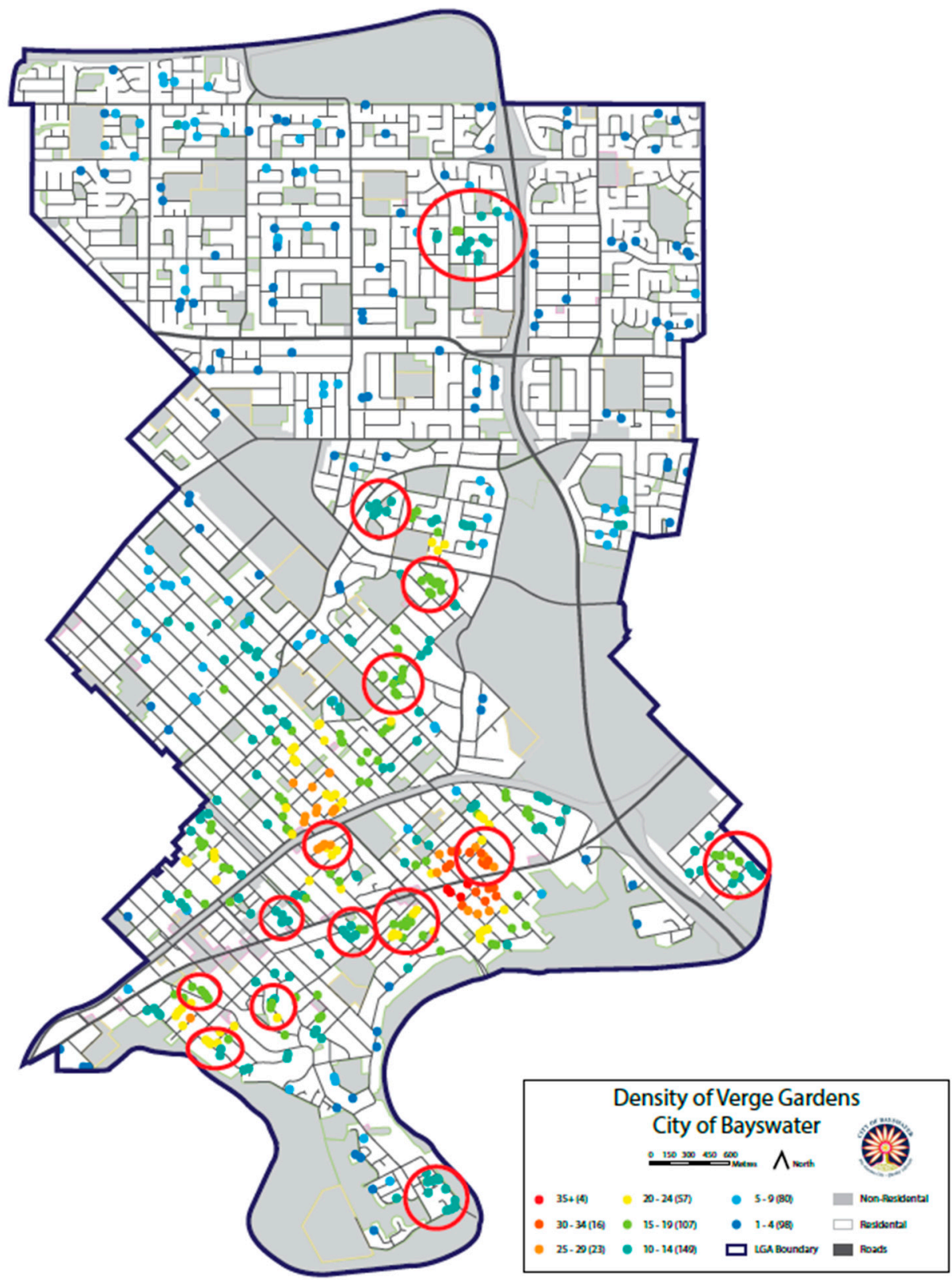

Figure 6. The density of verge gardens (per $400 \mathrm{~m}$ ) within the City of Bayswater.

\subsection{Questionnaire Survey Results}

Most of the respondents belonged to the 65+ (48) and 45-54 (57) age groups. Over $60 \%$ of respondents have lived in their homes for over 9 years. Almost three quarters of respondents lived in a household with a size of one or two people. Over $97 \%$ of respondents owned their own house, compared to $3 \%$ who were renting. From the participants demographic data as shown in Figure 8, it is evident that the survey reached the focus group of the residents who lived a substantial duration of time in the City of Bayswater.

\subsubsection{Motivations and Perceptions of Verge Gardens}

The primary motivations for creating a verge garden were to attract wildlife $(n=121)$ and for aesthetic reasons $(n=117)$, followed by environmental reasons $(n=102)$ and easier upkeep than lawns $(n=97)$ (Figure 9a). Interestingly, a very low number $(n=10)$ of respondents claimed to be motivated by other factors. Some common responses for 'other' were 'to reduce weeds', 'discourage parking', and 'love of gardening'. 


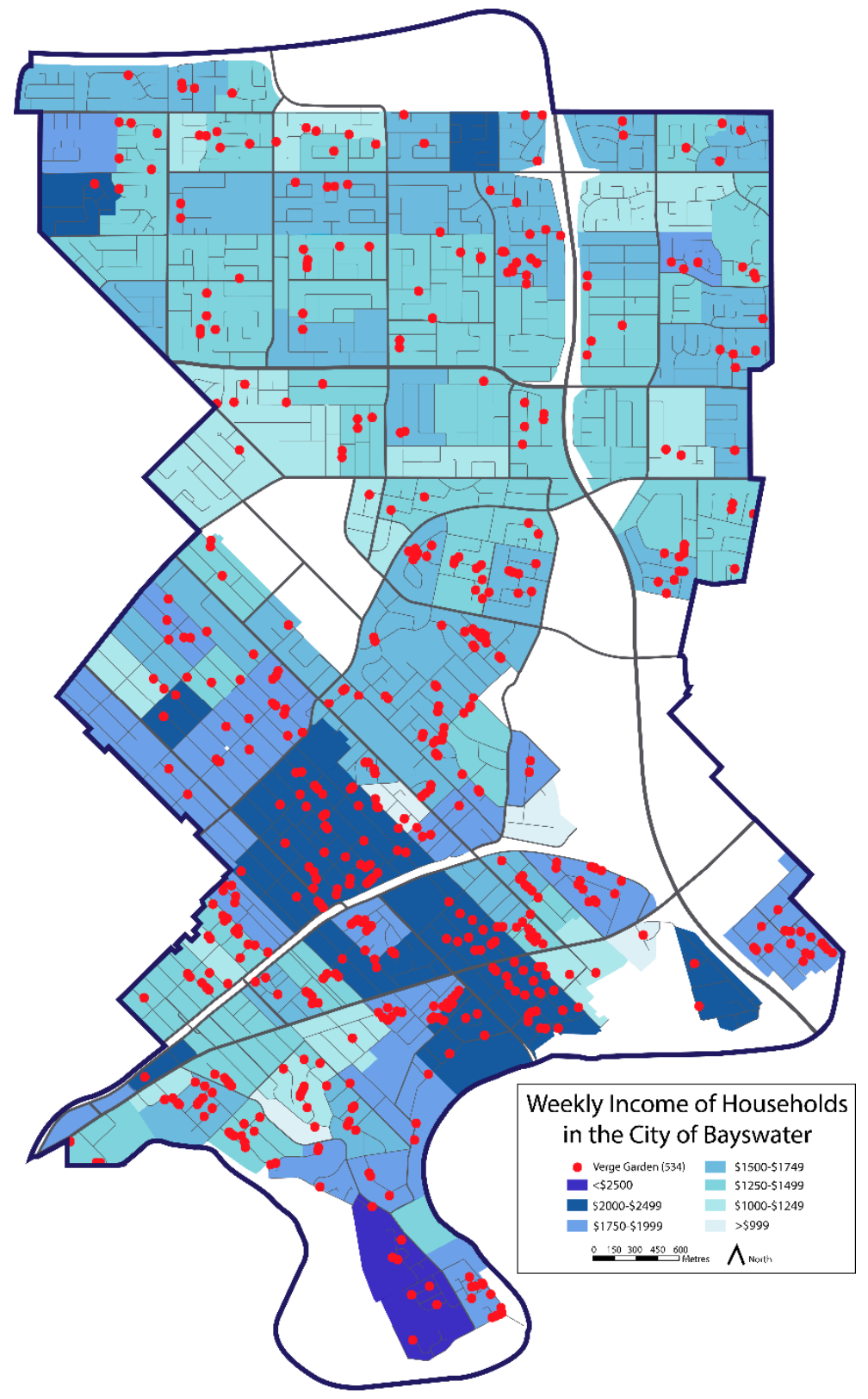

Figure 7. The weekly income of households and the presence of verge gardens.

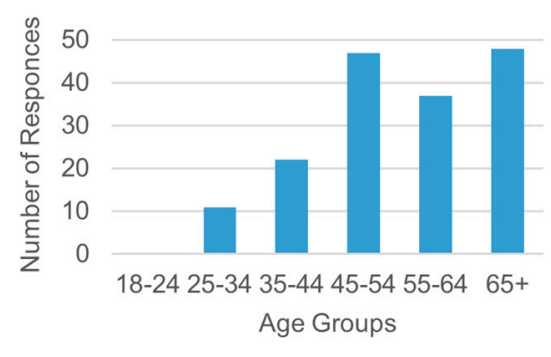

(a)

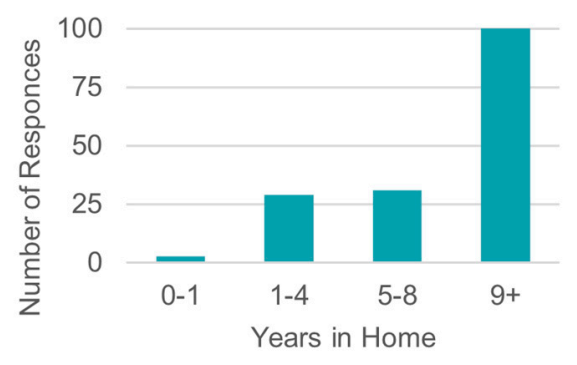

(b)

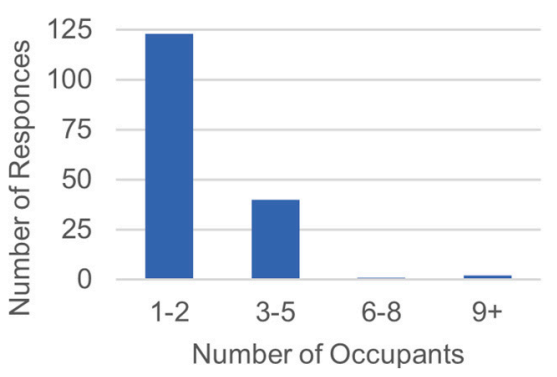

(c)

Figure 8. (a) The distribution of age groups of questionnaire respondents; (b) the number of years respondents have lived in their home; (c) the number of occupants that live within the home of respondents. 


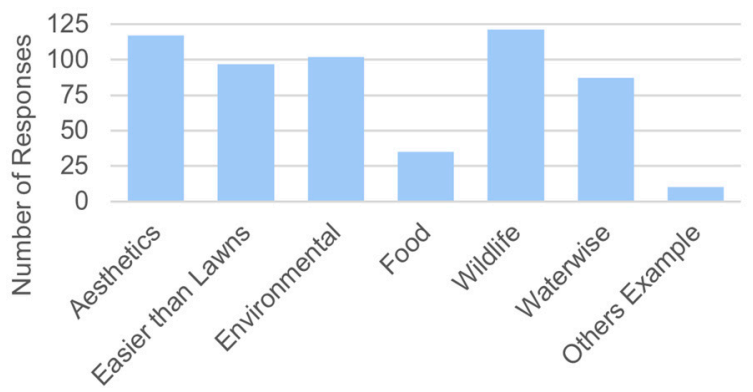

(a)

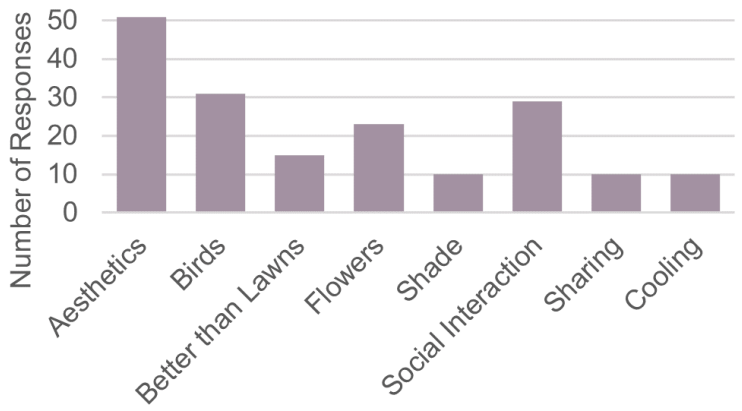

(b)

Figure 9. (a) The number of times a motivation was mentioned by the respondents (multiple responses counted, total responses $=615$ ); $(\mathbf{b})$ types of values added to the street or local environment by the verge gardens.

Respondents were asked to comment on what values their garden provides to the street or local environment. The qualitative responses were categorised into short descriptions: aesthetics, birds, better than lawns (which is costly to maintain), flowers, shade, social interaction, sharing, and cooling (Figure $9 b$ ). The top self-assessed amenity was aesthetics $(n=51)$, followed by birds $(n=31)$ and social interaction $(n=29)$. Many respondents claimed that their verge garden provided 'aesthetics' as an amenity to the street. Some other notable responses were 'shade', 'cooling effect', and 'flowers'.

\subsubsection{Cost}

The average cost to establish a verge garden as reported by the respondents was $>$ AUD 250 (Figure 10a). A small number of gardens were mentioned to be over AUD 1000 and this being due to reticulation or irrigation costs. Equation (1) below was used to find an estimate of the cost per $\mathrm{m}^{2}$. This data was able to find the estimated cost to establish verge gardens at AUD 2.6 per $\mathrm{m}^{2}$.

$$
\begin{gathered}
\text { AUD per } \mathrm{m}^{2}=[(\text { Lower Median Cost Bracket }) /(\text { Average Garden Size })+(\text { Upper Median Cost Bracket }) / \\
\text { (Average Garden Size })] / 2
\end{gathered}
$$

The annual cost to maintain a verge garden was >AUD 100 (Figure 10b). The main expenses mentioned were the cost of water usage and annual plant replacements. The majority of respondents $(87 \%)$ reported spending less than $2 \mathrm{~h}$ on weekly maintenance (Figure 10c).

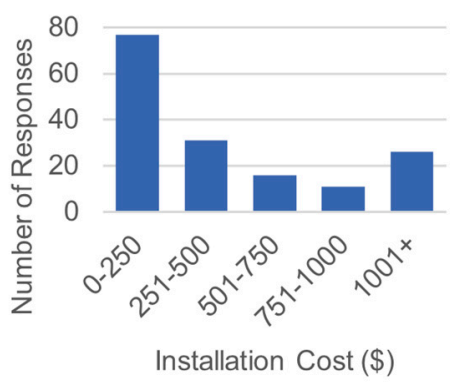

(a)

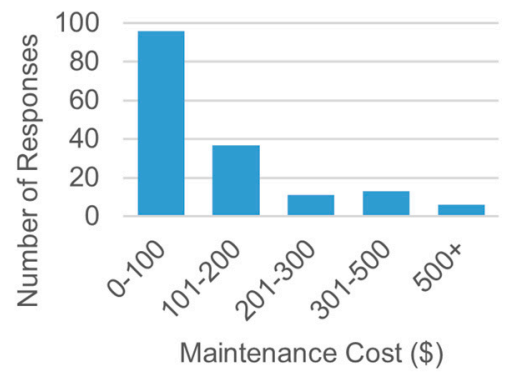

(b)

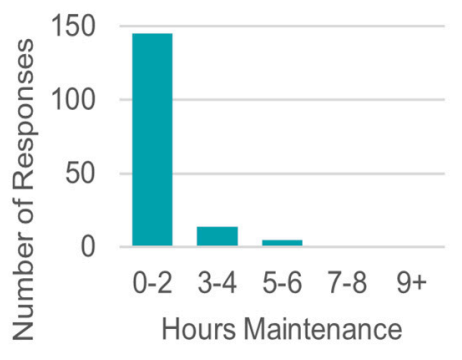

(c)

Figure 10. (a) The initial cost of installing verge gardens reported by respondents; (b) the cost of maintaining verge gardens; (c) number of hours spent maintaining the verge garden. 


\section{Discussion}

As cities become denser, this article highlights the potential for verge gardens to be an important 'non-traditional' green space to explore when supporting sustainable cities through regenerative landscapes [19]. Our study demonstrated the collective potential of the residential landscape in regard to supporting cities' ecosystem services, drivers for residents, and potential impacts for developing policy environments at the local level. These privately managed landscape pockets are created with various ecological and social motivations.

\subsection{Collective Benefit of Verge Garden}

Although verge gardens can look similar to a small parcel of land, collectively, they can provide large portions of land and nature links through cities. The number, arrangement, composition, and vegetation structure across these gardens can influence the delivered ecosystem services [10]. The total parks area within the City of Bayswater is $1.2 \mathrm{~km}^{2}$ (121 hectares), which accounts for 3\% of the total area. Verge gardens provide 1 hectare of self-maintained healthy vegetation to the local councils, which is equivalent to an additional neighbourhood park. Figure 11 highlights all green spaces zoned as public open spaces, not including regional parks. It provides a visual representation of the cumulative size of verge gardens in comparison to other public open spaces and the portion it takes up.

We can see that the majority of gardens are native and considered healthy. When considering how to build resilience to climate change or respond to sustainability challenges within the urban form, this article demonstrates the great potential for verge gardens to assist with integrated policy solutions. This includes the following services:

- Nature links or biodiversity corridors;

- $\quad$ Reducing urban heat; 4

- Food resilience;

- $\quad$ Rewilding and increasing biodiversity;

- Improving local air quality;

- Supporting an urban form, which provides for better community physical and mental health;

- $\quad$ Place making and connected communities;

- $\quad$ Reduce crime through CEPTED principles;

- Water sensitive cities.

Many studies have found that the verges have a high potential for biodiversity and ecosystem services, especially when planted with vegetation other than turf [5]. Even the use of exotic plants, such as perennial flowers and ornamental shrubs, supports diversity and environmental health [23].

\subsection{Motivations for Uptake}

Previous studies found that gardens were influenced by close neighbours, local styles, and the ecology of prestige [6]. Social and cultural factors have a great impact on verge gardens within the city council area. In previous studies on verge gardens, it was found that these processes are typically cultural and socio-economic [23]. Cultural factors are the influences of the social norm and community incentives (awards and certifications). Socio-economic factors include income, housing price, age, and age of the house.

It was noted in this study that the southern area has a higher density of verge gardens with a higher average income and smaller household size. Therefore, this increased verge take-up is thought to represent the greater value of land in the southern area and lower private green spaces available as a result of the higher density. 


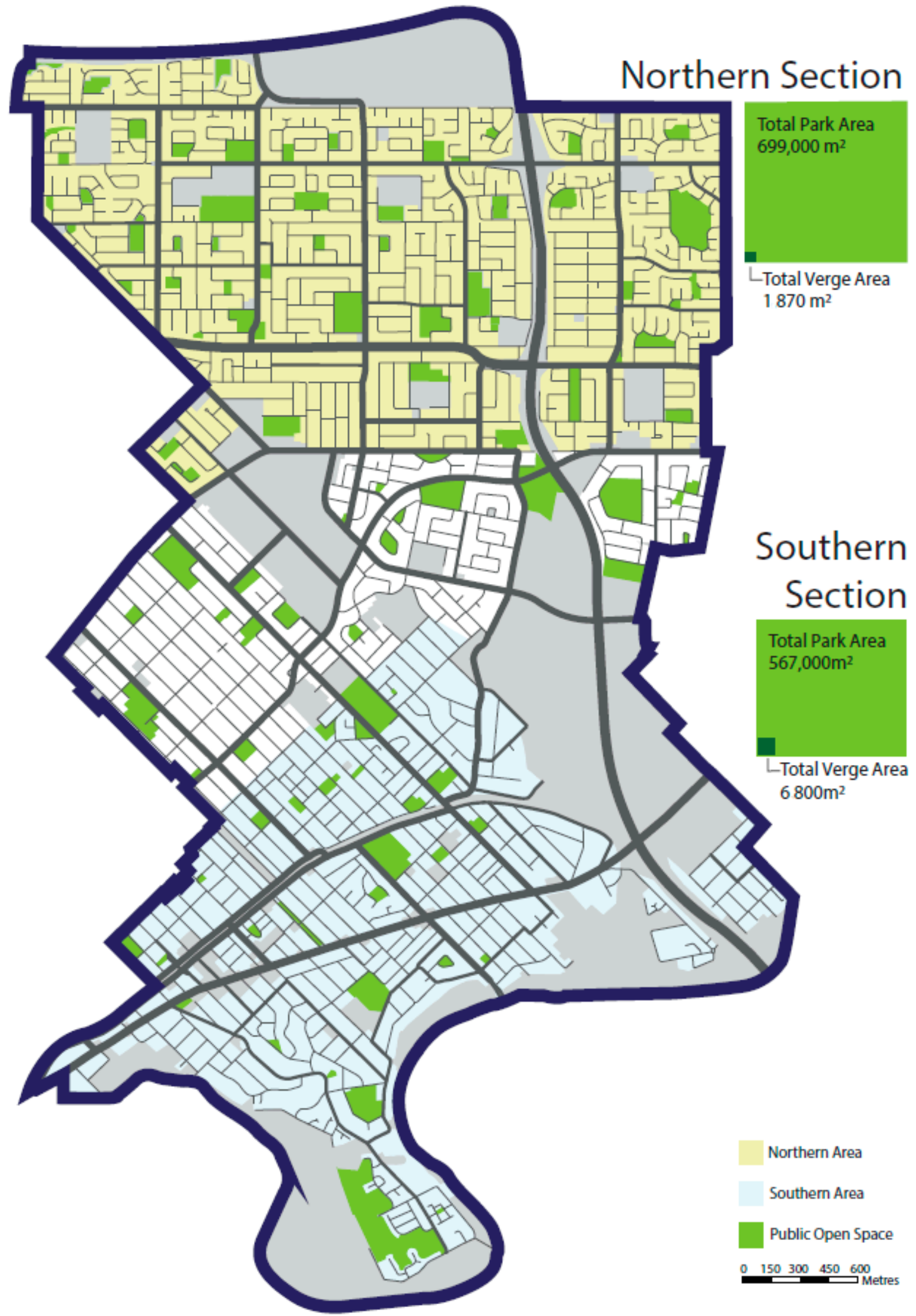

Figure 11. Collective public open space within the City of Bayswater. 
Comparing this to the demographic data from the residents' survey, we found the majority of respondents were retirees, with an average of one to two people per household. However, such data are unable to justify if socio-economic factors play a role in the uptake of verge gardens. Previous studies into verge gardens found that socio-economic characteristics may play a minor role in the uptake but could be primary reasoning for clustering [23]. Further research needs to be conducted to determine the socio-economic impacts on the clustering and uptake of verge gardens.

A study into Australian gardens found that households living next to semi-natural bushland were more likely to interact and encourage nature into their gardens [37]. This could be one factor for the greater verge garden densities in the southern portion of the site area. The southern boundary of the council is the Swan River, which is bordered by natural landscapes, and due to the topography of the land, many households have some connection with the river. This could be a strong reason for larger densities of gardens within this portion of the council. More research into this idea could provide interesting data on the link to natural landscapes and the uptake of verge gardens.

As noted in this paper, there are many reasons why making over verges from older forms to verge gardens can provide better value to the residents and the community. The functions of good communication, community education, and behaviour change are simple and clear messaging. In the resident survey, the four top drivers for people to makeover their verges were: to attract wildlife, amenity, environmental reasons, and that it was easier to upkeep than lawns. From this research, the authors are thus putting forward that community education or public relations approaches to this matter should focus on these four benefits for the verge custodian.

\subsection{Social Mimicky and the Clustering Effect}

This has been reproduced in similar studies, which found that there was a higher chance of imitation if the presence of verge gardens was less than $11 \%$ citywide [21]. There was evidence of mimicking with the use of similar or flora choices amongst gardens on the same street. A study in Montreal found that the front gardens of those who lived adjacent to each other had a higher degree of similarity regarding content and form [39]. Interestingly, the questionnaire highlighted residences would not admit to mimicking other gardens but would specify that others copied them. To corroborate with this idea, a study in Tasmania found that instead of mimicking neighbours' gardens, residents would do the opposite or be deliberately different [40].

Goddard and Dougill [6] describe 'catalyst behaviours' that can provide positive follow-on effects and change wider behaviours. This survey indicated that this principle is likely to apply to verge gardens, where a small number of one to three verge gardens can catalyse more neighbours into verge use. The potential policy application of this thinking is setting a policy environment that provides an early adopter benefit, such as funding to establish verge gardens in streets that do not currently have verge gardens through the notion of 'catalyst behaviours', which would then encourage more residents in the neighbourhood to adopt the practice.

In the City of Bayswater, there is an annual completion for the 'best verge garden'. Many studies have found that the upkeep of front gardens is related to how they attempt to uphold their social status, and there are social pressures to ensure one's garden is up to standard [6]. From the residents' survey, we could see the great sense of pride a verge garden brought, with residents claiming that it beautified their street and compared it to neighbours with unkempt lawns. There were also comments received from neighbours saying how beautiful their gardens were.

It is interesting to note that the surveys tend to support the previous research on clusters and social mimicry and may relate to some clusters in the City of Bayswater. One specific driver for this may be the observed increase of social interaction at the street level by survey respondents. That being said, there is a logical speculation that residents who 
see the benefits of a verge garden on a walk may be more motivated to implement one of their own. Further research is currently being proposed to better evidence this thinking.

The research identified that the average cost of making over a verge was AUD250 or AUD 2.60 per $\mathrm{m}^{2}$. In regard to policymakers, it was noted that there was a variation in the resources or grants local governments provided to their communities to support verge makeovers. Through this research, it was noted that often there was a fixed annual budget to support these programmes, which limited the total number of successful applicants each year. The challenge for the local government in these cases is that they would like to maximise the number of participants they can support whilst ensuring that the size of the grant provides an adequate driver to remove the financial barriers to residents making over their verges.

\section{Conclusions}

The article has considered previous related research and considered it in the context of local government areas. The study investigates the characteristics of the verge gardens and motivations and drivers for adopting verge gardens in the Western Australian context.

The verge gardens' audit found that native vegetation is the dominant verge garden type followed by ornamental. Food production (plants/vegetables) was the least frequent verge garden approach. The study has found that social, environmental, and personal drivers are the primary motivators for residents to adopt verge gardens in the local council area of Western Australia. Attracting wildlife and birds, and environmental aspects, including waterwise practice, were the key environmental motivators. Aesthetics, flowers, social interactions, and social mimicry (motivated by the neighbours) seem to be the critical social motivation. Easy maintenance seems to be the critical personal motivation for adopting verge gardens.

In considering aspects from this article that may be able to be directly applied to the local government policy setting, the authors have identified several key policy considerations:

(1) Share the benefits of verge gardens and reasons for why residents are converting their grey spaces to green spaces. The article identifies a broad range of benefits to residents if they have a verge garden. The survey highlights four self-reported benefits of verge gardens from the residents who self-improved their verges. When considering science translation, simplified plain English approaches are the contemporary approach. This research identifies what are likely to be the four greatest benefits of verge gardens that resonate with residents. Local government funding provides seed funding for resident verge makeovers. The article identifies the range of costs for residents to makeover their verge. The identified average self-reported cost of AUD 2.60 per $\mathrm{m}^{2}$ can help anchor the minimum makeover cost for a resident and in turn help government officials consider the balance of cost in supporting resident verge makeovers within what are normally capped funding budgets.

(2) Consider the potential impacts of social mimicry on the adoption of verge gardens by residents. Whilst further research is required to provide better evidence for this thinking, if looking across a local government that has a disproportionate uptake of verge gardens, using seed funding in low take-up areas may add a pull factor for residents in that area to take up the conversion of turning their grey spaces into green spaces. This could be through seeding example verge gardens in neighbourhoods, which essentially provides alternative vegetation templates.

(3) Consider integrating funding for verge garden makeovers as a feature of the long-term capital works programs. Local governments have traditionally renewed their assets with support of a long-term financial plan that biases towards the hard engineering costs. In this study, it was noted that the construction of a footpath may lead to an increased appetite for residents to create a verge garden. The opportunity then has been identified for local governments to integrate verge garden grant funding with their footpath upgrades to catalyse residents into growing verge gardens along new 
walkways, in turn proving a network of walkable streets, with the range of benefits provided by green spaces identified in this report.

(4) Consider the contributions verge gardens can make as part of the pandemic-sensitive spaces. There is a role for improving the uptake of verge gardens in thinking of the future urban form of cities, and their response to COVID-19 and more pandemicresilient cities, specifically, social distancing pods. Streets and footpaths provide opportunities for socially distanced exercise and passive recreation in a pandemic. Improved health, connection, and equity outcomes can be achieved in a pandemic through greener streets, with more verge gardens. Benefits to a local government can be achieved through incorporating verge gardens as social distancing pods into their pandemic-sensitive urban planning strategies.

Overall, this study demonstrates the opportunity for how residents with the support of their local government can undertake the small action of 'greening their verge' and their cumulative impacts on building sustainable cities. These benefits can be borne at the lot, street, and city level. The article also highlights the role for urban planning to think beyond its traditional roots to respond to the current climate and sustainability emergency cities are facing.

There is considerable potential for further research, especially in further investigating the potential of using catalyst behaviours and social mimicry to spread the uptake of verge gardens.

Author Contributions: Conceptualization, methodology and results, S.H.; writing of results and discussion, J.M.; introduction, conclusion, and editing, M.S.H.S.; structure, introduction and editing, A.Z. All authors have read and agreed to the published version of the manuscript.

Funding: This research received no external funding.

Institutional Review Board Statement: The research was approved by Curtin Human Research Ethics Committee (HRE2019-0457).

Informed Consent Statement: Respondents were required to read the information sheet attached with the questionnaire, which informs them of the purpose of the research and tick the box stating they consent to undertaking the questionnaire.

Acknowledgments: The authors acknowledge the contribution of the City of Bayswater for supporting the fieldwork. The authors would like to thank the anonymous reviewers who have provided valuable comments and suggestions to improve the quality of the article.

Conflicts of Interest: The authors declare no conflict of interest.

\section{References}

1. WHO. Climate Change and Health; World Health Organization: Geneva, Switzerland, 2018.

2. WaterCorp. How to Create a Waterwise Verge: Guidance for Householders, 2020; Water Corporation: Perth, Australia, 2020.

3. Scudder, G.G.E. The Importance of Insects. In Insect Biodiversity: Science and Society; Foottit, R.G., Adler, P.H., Eds.; Wiley-Blackwell: Berlin, Germany, 2017; pp. 9-25.

4. Sánchez-Bayo, F.; Wyckhuys, K.A. Worldwide decline of the entomofauna: A review of its drivers. Biol. Conserv. 2019, 232, 8-27. [CrossRef]

5. Warrant, E.; Frost, B.; Green, K.; Mouritsen, H.; Dreyer, D.; Adden, A.; Brauburger, K.; Heinze, S. The Australian Bogong moth Agrotis infusa: A long-distance nocturnal navigator. Front. Behav. Neurosci. 2016, 10, 77. [CrossRef] [PubMed]

6. Goddard, M.A.; Dougill, A.J.; Benton, T.G. Why garden for wildlife? Social and ecological drivers, motivations and barriers for biodiversity management in residential landscapes. Ecol. Econ. 2013, 86, 258-273. [CrossRef]

7. PerthNRM. ReWild; Perth NRM: Perth, Australia, 2021.

8. Bolleter, J. On the verge: Re-thinking street reserves in relation to suburban densification. J. Urban Des. 2016, 21, 195-212. [CrossRef]

9. WAPC. Perth and Peel at 3.5 Million (Draft)—Strategic Land Use Plan; Western Australian Planning Commission: Perth, Australia, 2015.

10. Lin, B.B.; Meyers, J.A.; Barnett, G.B. Establishing priorities for urban green infrastructure research in Australia. Urban Policy Res. 2019, 37, 30-44. [CrossRef]

11. Young, E. Get Out There and Do It: Perth Council Ditches Street Verge Rulebook, in WAtoday; WAtoday: Perth, Australia, 2017.

12. UN. The World's Cities in 2018; United Nations: New York, NY, USA, 2018.

13. ABS. Census of Population and Housing: Reflecting Australia; Australian Bureau of Statistics: Canberra, Australia, 2018. 
14. ABS. Regional Population-Statistics About the Population and Components of Change (Births, Deaths, Migration) for Australia's Capital Cities and Regions; Australian Bureau of Statistics: Canberra, Australia, 2021.

15. Matthews, J.; Akhtar-Khavari, A. Contributing to Nature's Recovery through Urban Agriculture. J. Vasyl Stefanyk Precarpathian Natl. Univ. 2018, 5, 45-54. [CrossRef]

16. IPCC. Climate Change 2021: The Physical Science Basis. Contribution of Working Group to the Sixth Assessment Report of the Intergovernmental Panel on Climate Change; Intergovernmental Panel on Climate Change: Cambridge, UK, 2021.

17. Zinia, N.J.; McShane, P. Ecosystem services management: An evaluation of green adaptations for urban development in Dhaka, Bangladesh. Landsc. Urban Plan. 2018, 173, 23-32. [CrossRef]

18. WaterCorp. Climate Change \& WA, Water Corporation; Water Corporation: Perth, Australia, 2021.

19. UN. Transforming Our World: The 2030 Agenda for Sustainable Development, 2015. Sustainable Development Goals; United Nations: New York, NY, USA, 2015.

20. Brun, M.; Di Pietro, F.; Bonthoux, S. Residents' perceptions and valuations of urban wastelands are influenced by vegetation structure. Urban For. Urban Green. 2018, 29, 393-403. [CrossRef]

21. Hunter, M.C.R.; Brown, D.G. Spatial contagion: Gardening along the street in residential neighborhoods. Landsc. Urban Plan. 2012, 105, 407-416. [CrossRef]

22. Ligtermoet, E.; Ramalho, C.E.; Martinus, K.; Chalmers, L.; Pauli, N. Stakeholder Perspectives on the Role of the Street Verge in Delivering Ecosystem Services; Clean Air and Urban Landscapes Hub: Melboune, Australia, 2021.

23. New, T.R.; Sands, D.P.; Taylor, G.S. Roles of roadside vegetation in insect conservation in Australia. Austral Entomol. 2021, 60, 128-137. [CrossRef]

24. Chen, R.; You, X.-Y. Reduction of urban heat island and associated greenhouse gas emissions. Mitig. Adapt. Strateg. Glob. Change 2020, 25, 689-711. [CrossRef]

25. Cameron, R.W.; Blanuša, T.; Taylor, J.E.; Salisbury, A.; Halstead, A.J.; Henricot, B.; Thompson, K. The domestic garden-Its contribution to urban green infrastructure. Urban For. Urban Green. 2012, 11, 129-137. [CrossRef]

26. Xiao, Y.; Li, Z.; Webster, C. Estimating the mediating effect of privately-supplied green space on the relationship between urban public green space and property value: Evidence from Shanghai, China. Land Use Policy 2016, 54, 439-447. [CrossRef]

27. Biernacka, M.; Kronenberg, J.; Łaszkiewicz, E. An integrated system of monitoring the availability, accessibility and attractiveness of urban parks and green squares. Appl. Geogr. 2020, 116, 102152. [CrossRef]

28. Spennemann, D. Exercising under COVID-2x: Conceptualizing Future Green Spaces in Australia's Neighborhoods. Urban Sci. 2021, 5, 93. [CrossRef]

29. Marshall, A.J.; Grose, M.J.; Williams, N.S. From little things: More than a third of public green space is road verge. Urban For. Urban Green. 2019, 44, 126423. [CrossRef]

30. CoV. Adopt a Verge, City of Vincent; City of Vincent: Perth, Australia, 2021.

31. CoC. Waterwise Verge Rebate, City of Cockburn; City of Cockburn: Perth, Australia, 2021.

32. WaterCorp. Expanded Verge Rebate Scheme; Water Corporation: Perth, Australia, 2019; Volume 2019.

33. ABS. Bayswater (WA), 2016; Australian Bureau of Statistics: Canberra, Australia, 2016.

34. CoB. Public Health and Wellbeing Plan 2019-2024; City of Bayswater: Perth, Australia, 2019.

35. CoB. Local Histroy; City of Bayswater: Perth, Australia, 2022.

36. ABS. Noranda (WA), 2016; Australian Bureau of Statistics: Canberra, Australia, 2016.

37. ABS. Maylands (WA), 2016; Australian Bureau of Statistics: Canberra, Australia, 2016.

38. McNally, K. Design Guidelines for Walkable Communties; University of Cincinnati: Cincinnati, OH, USA, 2010.

39. Zmyslony, J.; Gagnon, D. Residential management of urban front-yard landscape: A random process? Landsc. Urban Plan. 1998, 40, 295-307. [CrossRef]

40. Kirkpatrick, J.; Davison, A.; Daniels, G. Resident attitudes towards trees influence the planting and removal of different types of trees in eastern Australian cities. Landsc. Urban Plan. 2012, 107, 147-158. [CrossRef] 